\title{
SPECIAL ISSUE "INTUITIONISTIC FUZZY THEORY AND ITS APPLICATION IN ECONOMY, TECHNOLOGY AND MANAGEMENT"
}

\author{
Peide LIU \\ School of Management Science and Engineering, Shandong University of Finance and Economics, \\ 250014 Jinan Shandong, China
}

Received 05 April 2016; accepted 28 April 2016

\section{Acknowledgements}

First of all, we would like to thank all the authors for their provided high quality papers to this special issue and help in showing the usefulness of "Intuitionistic fuzzy theory and its application in economy, technology and management". Then, we would like to thank all the reviewers who provided the very helpful comments that improved these papers and guaranteed the quality of this special issue. Further, we would also like to thank the Professor Zaiwu Gong from Nanjing University of Information Science and Technology, who provided some helps for this introduction to the special issue. Finally, we would like to thank Professor Edmundas Kazimieras Zavadskas, Editor in Chief of Technological and Economic Development of Economy, for proposing to publish this special issue. In addition, thank the support from the National Natural Science Foundation of China (Nos. 71471172 and 71271124) and the Special Funds of Taishan Scholars Project of Shandong Province.

\section{Uncertainty theory and intuitionistic fuzzy sets}

In the economic, technical and managerial decision-making of the decision makers' subjective participation, they can use standardized knowledge to normalize the decision thinking process so as to achieve their decision-making purposes by concerning the qualitative factors or a mix of qualitative and quantitative decision factors which played a decisive role in reflecting peoples' judgment and experience. Uncertainty theories, such as fuzzy sets (Zadeh 1965), interval-valued fuzzy sets (Zadeh 1965), grey sets (Deng 1998; Liu, Lin

Corresponding author Peide Liu

E-mail:peide.liu@gmail.com 
2006), intuitionistic fuzzy (Atanassov 1986), Vague (Gau, Buehrer 1993), neutrosophic sets (Smarandache 1999), the linguistic term sets and computing with words (CWW) (Zadeh 1975a, 1975b, 1975c; Herrera et al. 2008) etc. are the effective tools to solve the decision making problems with the qualitative and quantitative nature together in economic and management decision-making.

The knowledge representation by intuitionistic fuzzy set is a kind of intuitive behavior of human advanced thinking in essence. Such as the interval fuzzy knowledge, grey knowledge, and intuitionistic fuzzy knowledge, all of them were called intuitive knowledge by Dubois and Gottwald (2005). Intuitive knowledge development is a necessity of economic, technical and managerial decision making which coincides with the transition from the industrial society to the information society. In addition, the intuitive knowledge was developed from one to three dimensions (i.e. fuzzy numbers, intervals, three dimensional discrete points) in terms of data describing, and was developed from subjectivity to the combination of subjectivity and objectivity in considering preference expression, and it was also developed from rough to fine on simulating human decision making and behaviors.

\section{Evolution of intuitive decision-making knowledge}

The evolution of intuitive knowledge and the development of operational systems have approximately experienced 50 years.

(1) Interval fuzzy knowledge. In the periods of the third science and technology revolution, there is a urgent need to find a tool for identifying the qualitative problems with the emergence of all kinds of "man-machine control system". In 1965, Cybernetics expert, Professor Zadeh (1965) proposed fuzzy set theory, which opened up a new era of quantitative analysis for qualitative problems. As early as in 1966, Moore (1966) has put forward the concept of interval analysis, and he focused on the operational systems of interval numbers. However, these operational systems are still limited to algebraic arithmetic systems, and they are not reversible. This is also destined to make the interval operational theory not make a breakthrough in the conventional conditions.

In 1975, Zadeh (1975a, 1975b, 1975c) put forward a theory of interval fuzzy set which is an extension of fuzzy theory by generalizing the ordinary fuzzy membership to an uncertain interval. Fuzzy interval arithmetic can better express the People's decision preference, i.e., although objective things cannot be cognized accurately, at least, its subject range of membership can be defined. Interval fuzzy sets referenced interval operational systems and the operational results are expressed by the approximate numerical values, which are gradually accepted by researchers in the field of decision making.

(2) Grey interval knowledge. In 1982, “The Control Problem of Grey System” by Deng (1982) is published in North Holland in 1982, which marked the birth of the grey system theory, and stressed the object of the research "extension is clear and definite and the intension is not clear and definite". By the grey interval, the decision maker's preference is expressed. Since 1993, Huang et al. (1993) has laid very important theoretical foundation for the study of grey planning as well as has greatly promoted the development of the grey multi-objective and grey multi-attribute decision making theory which are based on the 
optimization decision-making theory. In grey system, many scholars suggested that the decision interval were expressed by the linear parameters so as to avoid the limitations of interval operations. The domain of grey preference is defined in $(-\infty,+\infty)$ while fuzzy preference interval are limited to $[0,1]$, thus, the grey interval preference knowledge can emphasize more on the objectivity of data.

(3) Intuitionistic fuzzy knowledge. In 1986, Atanassov (1986) proposed the intuitionistic fuzzy sets which are the extensions of fuzzy sets, and then he further established the relationship between intuitionistic fuzzy sets and interval fuzzy sets in 1989 (Atanassov, Gargov 1989). Intuitionistic fuzzy sets can express the decision maker's preference by three discrete values i.e. membership degree, non-membership degree and hesitation degree, which are the discrete expressions of continuous interval fuzzy values.

In the field of group decision making, about People's reactions to the evidence or opinions, there are three kinds of situations in general, i.e., affirmation, negation and uncertainty, the People's behavior recognition process is similar to the thoughts of intuitionistic fuzzy sets. The normal operations cannot handle the intuitionistic fuzzy system, and new operational laws have been built (Atanassov 1986; Liu 2014; He et al. 2014). Further, the successful applications of the intuitionistic fuzzy sets theory in pattern recognition, clustering analysis, knowledge inference and other areas have greatly promoted the developments of unconventional operational systems in intuitionistic fuzzy systems.

(4) Knowledge of intuitionistic fuzzy theory extensions. Because of the complexity of objective things, the fuzziness of human thinking, as well as the limits of decision time, cost and the decision-maker's knowledge, there are still many limitations to express the decision information in the form of intuitionistic fuzzy sets. On the one hand, sometimes, it is difficult for people to express membership degree and non-membership degree by real numbers, so, there are a lot of researches about the extensions of intuitionistic fuzzy sets, for example, the membership degree and non-membership degree are extended to interval numbers (Atanassov, Gargov 1989), triangular fuzzy numbers (Zhang, Liu 2010), fuzzy numbers (Wang, Zhang 2009) and linguistic variables (Chen et al. 2015). Obviously, these extensions have improved the ability of intuitionistic fuzzy sets to express uncertain information. On the other hand, the decision makers can give the membership degree and non-membership degree of the intuitionistic fuzzy set only for a particular concept, in order to make the membership or non-membership belonged to some a special value and not to a concept, many researchers combined intuitionistic fuzzy sets with fuzzy numbers (Wang, Zhang 2009), linguistic variables (Wang, Li 2009; Liu 2013a) and uncertain linguistic variables (Liu, Jin 2012), and proposed intuitionistic trapezoidal fuzzy numbers, intuitionistic linguistic variables, intuitionistic uncertain linguistic variables and so on to indicate the degrees of membership and non-membership to some a fuzzy number, linguistic variable, uncertain linguistic variable. Clearly, these extensions, which fully considered the merits of intuitionistic fuzzy sets and fuzzy numbers or linguistic variables, uncertain linguistic variables, are of greater generality, and can easily express the complex realistic decision information. 


\section{The research progress of intuitionistic fuzzy sets in economy, technology and management decision-making field}

In recent years, the intuitionistic fuzzy sets have attracted wide attentions, and have made important research progress in economy, technology and decision-making management fields (Mardani et al. 2015).

(1) Research on the fundamental theory of intuitionistic fuzzy sets, include: the operational laws, information entropy, distances, similarity and comparison methods for intuitionistic fuzzy sets; aggregation function and aggregation operators for intuitionistic fuzzy information, such as generalized aggregation operator, Sugeno and Choquet integral operators, prioritized aggregation operators, power average operators, Bonferroni mean, dependent aggregation operators, density weighted average operators and so on (Zavadskas et al. 2014; Liu 2013a, 2013b; Liu, Yu 2013; Liu et al. 2014; Liu, Wang 2014).

(2) Research on the decision making methods, mainly include: extensions of the traditional decision making methods to intuitionistic fuzzy sets, such as TOPSIS (Wang et al. 2015), VIKOR (Peng et al. 2015), ELECTRE (Liu, Zhang 2011; Ebrahimnejad et al. 2015; Hashemi et al. 2016), TODIM (Li et al. 2015), DEMATEL (Govindan et al. 2015), MOORA (Pérez-Domínguez et al. 2015), MULTIMOORA (Zavadskas et al. 2015), COPRAS (Hajiagha et al. 2013a), DEA (Hajiagha et al. 2013b; Liu et al. 2014) and so on are extended to intuitionistic fuzzy information, we can call these extensions the extended decision making methods; another decision making methods are based on the aggregation operators, and can provide the comprehensive values by aggregating the criteria information.

(3) Research on intuitionistic fuzzy group decision-making, mainly include: the construction of aggregation rules for intuitionistic fuzzy information, the optimization modeling construct, conflict measure models of group members, group consistency analysis models and the optimal selection of the project etc.

(4) Research on applications of intuitionistic fuzzy sets. There are a lot of applications in real decision making based on the intuitionistic fuzzy sets (Hajiagha et al. 2013a), such as scheme selection, performance evaluation, pattern recognition, computing with words, clustering analysis, knowledge inference, medical diagnosis and so on. These researches include information acquisition, optimization model construction, algorithm design, simulation and analogue test, system development, and they are also the extension of general multi-attribute decision-making methods (Hajiagha et al. 2015).

\section{About the papers of this special issue}

Now, we briefly summarize the contents of this special issue in which there are five new contributions on the theory of intuitionistic fuzzy sets and the methods of multiple attribute decision making or multiple attribute group decision making based on intuitionistic fuzzy sets. These contributions can be divided into three groups. 
The first one includes two papers which provide some new theory for intuitionistic fuzzy set, such as novel score function and accuracy function, the spherical distance for intuitionistic fuzzy sets, and inclusion comparison possibility for interval-valued intuitionistic fuzzy sets. The second group only covers one paper introducing the fuzzy ELECTRE outranking method with interval-valued intuitionistic fuzzy sets. The third group only includes one paper presenting novel fuzzy MCDM models based on significant aggregation operators.

There are three papers in the first group which introduces some new theory of IFS.

- Wu et al. in "An approach for MADM problems with interval valued intuitionistic fuzzy sets based on nonlinear functions" propose the nonlinear score, accuracy and hesitation functions of IVIFNs based on the normal distribution. The advantage of these nonlinear functions is that they have an additional variance value, which can have more information to rank IVIFNs than Xu and Chen's score function and Ye's accuracy function. In addition, authors also develop a nonlinearly optimized model to obtain attribute weights by integrating these nonlinear functions, and they further present an MADM approach in which two cases are considered: the attribute weight information is known and particularly known.

- Gong et al. in "The spherical distance for Intuitionistic fuzzy sets and its application in decision analysis" propose the spherical distance between two IFSs. The advantage is that it relies not only on their relative differences but also their absolute values. Authors generalize the properties of spherical distance measures between IFSs, and develop an optimization spherical distance model with IFS preference in group decision making.

- In the paper entitled "An inclusion comparison approach for multiple criteria decision analysis based on interval-valued intuitionistic fuzzy sets", by Chen, an inclusion comparison possibility defined on interval-valued intuitionistic fuzzy sets is proposed, and some important properties are investigated. Further, authors constructs a linear programming model (for consistent information) and an integrated, nonlinear programming model (for inconsistent information) to estimate the criterion weights and the optimal ranking order of the alternatives under an incomplete preference structure by considering the maximal comprehensive inclusion-based indices.

In addition, based on these new theories of IFS, authors propose the some decision making methods for MADM problems in which the attribute values take the form of IFS and attribute weight is known and particularly known.

There is one paper in the second group which introduces an extended ELECTRE outranking method for multiple criteria decision-making with interval-valued intuitionistic fuzzy sets.

- Chen in "An IVIF-ELECTRE outranking method for multiple criteria decisionmaking with interval-valued intuitionistic fuzzy sets" proposes an interval-valued intuitionistic fuzzy ELECTRE (IVIF-ELECTRE) method and applies it to multiple criteria decision analysis (MCDA) involving the multiple criteria evaluation/selection of alternatives. Author identifies inclusion comparison approach, concordance and discordance sets for each pair of alternatives, and determines the concordance 
and discordance indices using an aggregate importance weight score function and a generalized distance measurement between weighted evaluative ratings, respectively. Based on the concordance and discordance dominance matrices, two IVIF-ELECTRE ranking procedures are developed for the partial and complete ranking of the alternatives.

There is one paper in the third group which introduces intuitionistic trapezoidal fuzzy prioritized OWA operator.

- Liu et al. in "A multi-criteria decision-making method based on intuitionistic trapezoidal fuzzy prioritized OWA operator" proposes intuitionistic trapezoidal fuzzy prioritized ordered weighted aggregation (ITFPOWA) operator, and develops an approach to the multi-criteria decision-making with intuitionistic trapezoidal fuzzy numbers. The advantage is that this method considers the prioritized relationship among decision-making attributes and the attribute values take the form of intuitionistic trapezoidal fuzzy information.

In the applications to real decision making problems, the five new contributions have also good performances.

The method proposed by Wu et al. in "An approach for MADM problems with interval valued intuitionistic fuzzy sets based on nonlinear functions" was applied to solve the environmental performance evaluation problems.

The method proposed by Gong et al. in "The spherical distance for Intuitionistic fuzzy sets and its application in decision analysis" was applied to group decision making, pattern recognition, and medical diagnosis.

The method proposed by Chen in "An inclusion comparison approach for multiple criteria decision analysis based on interval-valued intuitionistic fuzzy sets" was applied to select the most suitable bridge construction method for the Su-Hua Highway Alternative Route Plan at the Hualian and Taidong areas in Taiwan.

The method proposed by Chen in "An IVIF-ELECTRE outranking method for multiple criteria decision-making with interval-valued intuitionistic fuzzy sets" was applied to select a suitable watershed site.

The method proposed by Liu et al. in "A multi-criteria decision-making method based on intuitionistic trapezoidal fuzzy prioritized OWA operator" was applied to the recruitment of human resource managers.

\section{References}

Atanassov, K. 1986. Intuitionistic fuzzy sets, Fuzzy Sets and Systems 20(1): 87-96. http://dx.doi.org/10.1016/S0165-0114(86)80034-3

Atanassov, K.; Gargov, G. 1989. Interval valued intuitionistic fuzzy sets, Fuzzy Sets and Systems 31(3): 343-349. http://dx.doi.org/10.1016/0165-0114(89)90205-4

Chen, Z.; Liu, P.; Pei, Z. 2015. An approach to multiple attribute group decision making based on linguistic intuitionistic fuzzy numbers, International Journal of Computational Intelligence Systems 8(4): 747-760. http://dx.doi.org/10.1080/18756891.2015.1061394 
Deng, J. L. 1982. Control problems of grey systems, Systems \& Control Letters 1(5): 288-294. http://dx.doi.org/10.1016/S0167-6911(82)80025-X

Deng, J. L. 1998. Grey group decision in grey relational space, The Journal of Grey System 3: 177-182.

Dubois, D.; Gottwald, S. 2005. Terminological difficulties in fuzzy set theory - the case of "Intuitionistic Fuzzy Sets", Fuzzy Sets and Systems 156(3): 485-491. http://dx.doi.org/10.1016/j.fss.2005.06.001

Ebrahimnejad, S.; Hashemi, H.; Mousavi, S. M.; Vahdani, B. 2015. A new interval-valued intuitionistic fuzzy model to group decision making for the selection of outsourcing providers, Economic Computation and Economic Cybernetics Studies and Research 49(2): 269-290.

Govindan, K.; Khodaverdi, R.; Vafadarnikjoo, A. 2015. Intuitionistic fuzzy based DEMATEL method for developing green practices and performances in a green supply chain, Expert Systems with Applications 42(20): 7207-7220. http://dx.doi.org/10.1016/j.eswa.2015.04.030

Gau, W. L.; Buehrer, D. J. 1993. Vague sets, IEEE Transactions on Systems, Man, and Cybernetics 3(2): 610-614. http://dx.doi.org/10.1109/21.229476

Hajiagha, S. H. R.; Hashemi, S. S.; Zavadskas, E. K. 2013a. A complex proportional assessment method for group decision making in an interval-valued intuitionistic fuzzy environment, Technological and Economic Development of Economy 19(1): 22-37. http://dx.doi.org/10.3846/20294913.2012.762953

Hajiagha, S. H. R.; Akrami, H.; Zavadskas, E. K.; Hashemi, S. S. 2013b. An intuitionistic fuzzy data envelopment analysis for efficiency evaluation under uncertainty: case of a finance and credit institution, E \& M Ekonomie a Management 16(1): 128-137.

Hajiagha, S. H. R.; Mandiraji, H. A.; Hashemi, S. S.; Zavadskas, E. K. 2015. Evolving a linear programming technique for MAGDM problems with interval valued intuitionistic fuzzy information, Expert Systems with Applications 42(23): 9318-9325. http://dx.doi.org/10.1016/j.eswa.2015.07.067

Hashemi, S. S.; Hajiagha, S. H. R.; Zavadskas, E. K.; Mahdiraji, H. A. 2016. Multicriteria group decision making with ELECTREIII method based on interval-valued intuitionistic fuzzy information, $A p$ plied Mathematical Modelling 40(2): 1554-1564. http://dx.doi.org/10.1016/j.apm.2015.08.011

He, Y. D.; Chen, H. Y.; Zhou, L. G.; Liu, J. P.; Tao, Z. F. 2014. Intuitionistic fuzzy geometric interaction averaging operators and their application to multi-criteria decision making, Information Sciences 259: 142-159. http://dx.doi.org/10.1016/j.ins.2013.08.018

Herrera, F.; Herrera-Viedma, E.; Martínez, L. 2008. A fuzzy linguistic methodology to deal with unbalanced linguistic term sets, IEEE Transaction on Fuzzy Systems 16(2): 354-370. http://dx.doi.org/10.1109/TFUZZ.2007.896353

Huang, G. H.; Baetz, B. W.; Party, G. G. 1993. A grey fuzzy linear programming approach for municipal solid waste management planning under uncertainty, Civil Engineering Systems 10(2): 123-146. http://dx.doi.org/10.1080/02630259308970119

Li, M.; Wu, C.; Zhang, L.; You, L. N. 2015. An intuitionistic fuzzy-TODIM method to solve distributor evaluation and selection problem, International Journal of Simulation Modelling 14(3): 511-524. http://dx.doi.org/10.2507/IJSIMM14(3)CO12

Liu, B.; Shen, Y.; Chen, X.; Wang, X. 2014. A partial binary tree DEA-DA cyclic classification model for decision makers in complex multi-attribute large-group interval-valued intuitionistic fuzzy decisionmaking problems, Information Fusion 18: 119-130. http://dx.doi.org/10.1016/j.inffus.2013.06.004

Liu, P. D. 2013a. Some generalized dependent aggregation operators with intuitionistic linguistic numbers and their application to group decision making, Journal of Computer and System Sciences 79(1): 131-143. http://dx.doi.org/10.1016/j.jcss.2012.07.001

Liu, P. D. 2013b. Some geometric aggregation operators based on interval intuitionistic uncertain linguistic variables and their application to group decision making, Applied Mathematical Modelling 37(4): 2430-2444. http://dx.doi.org/10.1016/j.apm.2012.05.032 
Liu, P. D. 2014. Some Hamacher aggregation operators based on the interval-valued intuitionistic fuzzy numbers and their application to Group Decision Making, IEEE Transactions on Fuzzy Systems 22(1): 83-97. http://dx.doi.org/10.1109/TFUZZ.2013.2248736

Liu, P. D.; Liu, Z. M.; Zhang, X. 2014. Some intuitionistic uncertain linguistic heronian mean operators and their application to group decision making, Applied Mathematics and Computation 230: 570-586. http://dx.doi.org/10.1016/j.amc.2013.12.133

Liu, P. D.; Jin, F. 2012. Methods for aggregating intuitionistic uncertain linguistic variables and their application to group decision making, Information Sciences 205: 58-71. http://dx.doi.org/10.1016/j.ins.2012.04.014

Liu, P. D.; Wang, Y. M. 2014. Multiple attribute group decision making methods based on intuitionistic linguistic power generalized aggregation operators, Applied Soft Computing 17: 90-104. http://dx.doi.org/10.1016/j.asoc.2013.12.010

Liu, P. D.; Yu, X. C. 2013. Density aggregation operators based on the intuitionistic trapezoidal fuzzy numbers for multiple attribute decision making, Technological and Economic Development of Economy 19(Supplement 1): S454-S470. http://dx.doi.org/10.3846/20294913.2013.881436

Liu, P. D.; Zhang, X. 2011. Research on the supplier selection of supply chain based on entropy weight and improved ELECTRE-III method, International Journal of Production Research 49(3): 637-646. http://dx.doi.org/10.1080/00207540903490171

Liu, S. F.; Lin, Y. 2006. Grey information: theory and practical applications. London: Spinger-Verlag.

Mardani, A.; Jusoh, A.; Zavadskas, E. K. 2015. Fuzzy multiple criteria decision-making techniques and applications - Two decades review from 1994 to 2014, Expert Systems with Applications 42(8): 4126-4148. http://dx.doi.org/10.1016/j.eswa.2015.01.003

Moore, R. 1966. Interval analysis. New York, Englewood Cliffs: Prentice Hall.

Peng, J. P.; Yeh, W. C.; Lai, T. C.; Hsu, C. B. 2015. The incorporation of the Taguchi and the VIKOR methods to optimize multi-response problems in intuitionistic fuzzy environments, Journal of the Chinese Institute of Engineers 38(7): 897-907. http://dx.doi.org/10.1080/02533839.2015.1037994

Pérez-Domínguez, L.; Alvarado-Iniesta, A.; Rodríguez-Borbón, I.; Vergara-Villegas, O. 2015. Intuitionistic fuzzy MOORA for supplier selection (MOORA versión difuso intuicionista para la selección de proveedores), Dyna 82(191): 34-41. http://dx.doi.org/10.15446/dyna.v82n191.51143

Smarandache, F. 1999. A unifying field in logics. neutrosophy: neutrosophic probability, set and logic. Rehoboth: American Research Press.

Wang, J. Q.; Zhang, Z. 2009. Multi-criteria decision-making method with incomplete certain information based on intuitionistic fuzzy number, Control and Decision 24: 226-230 (In Chinese).

Wang, J. Q.; Li, J. J. 2009. The multi-criteria group decision making method based on multi-granularity intuitionistic two semantics, Science \& Technology Information 33: 8-9 (In Chinese).

Wang, Y.; Xi, C.; Zhang, W.; Yu, D. 2015. Combined approach for government e-tendering using GA and TOPSIS with intuitionistic fuzzy information, PLOS ONE 10(7): e0130767. http://dx.doi.org/10.1371/journal.pone.0130767

Zadeh, L. A. 1965. Fuzzy sets, Information and Control 8(3): 338-353. http://dx.doi.org/10.1016/S00199958(65)90241-X

Zadeh, L. A. 1975a. The concept of a linguistic variable and its applications to approximate reasoning: Part I, Information Sciences 8(3): 199-243. http://dx.doi.org/10.1016/0020-0255(75)90036-5

Zadeh, L. A. 1975b. The concept of a linguistic variable and its applications to approximate reasoning: Part II, Information Sciences 8(4): 301-357. http://dx.doi.org/10.1016/0020-0255(75)90046-8

Zadeh, L. A. 1975c. The concept of a linguistic variable and its application to approximate reasoning: Part III, Information Sciences 9(1): 43-80. http://dx.doi.org/10.1016/0020-0255(75)90017-1 
Zavadskas, E. K.; Antucheviciene, J.; Hajiagha, S. H. R.; Hashemi, S. S. 2014. Extension of weighted aggregated sum product assessment with interval-valued intuitionistic fuzzy numbers (WASPASIVIF), Applied Soft Computing 24: 1013-1021. http://dx.doi.org/10.1016/j.asoc.2014.08.031

Zavadskas, E. K.; Antucheviciene, J.; Hajiagha, S. H. R.; Hashemi, S. S. 2015. The interval-valued intuitionistic fuzzy MULTIMOORA method for group decision making in engineering, Mathematical Problems in Engineering, Article Number: 560690. http://dx.doi.org/10.1155/2015/560690

Zhang, X.; Liu, P. D. 2010. Method for aggregating triangular fuzzy intuitionistic fuzzy information and its application to decision making, Technological and Economic Development of Economy 16(2): 280-290. http://dx.doi.org/10.3846/tede.2010.18 